\title{
The Impact of Obesity on Surgical Complications and Disease Recurrence in Endometrial Cancer: A Retrospective Study of 267 Patients
}

\author{
Khaled Gaballa ${ }^{1}$, Mohamed Abdelkhalek ${ }^{1}$, Basel Refky ${ }^{1}$, Basma Gadelhak ${ }^{\text {, }}$ Engy M. \\ Aboelnaga ${ }^{3}$, Wafaa El-Beshbishi ${ }^{3}$
}

${ }^{1}$ Department of Surgery, Oncology Center-Mansoura University, Mansoura, Egypt; ${ }^{2}$ Department of Radiology, Faculty of Medicine, Mansoura University, Mansoura, Egypt; ${ }^{3}$ Department of Clinical Oncology and Nuclear Medicine, Faculty of Medicine, Mansoura University, Mansoura, Egypt.

Background: Obesity is a well-known risk factor for many health problems including endometrial cancer. In addition, it may act as an obstacle to achieving optimal treatment of endometrial cancer and may be associated with disease recurrence. Aim: To explore the impact of obesity on the operative procedure, recurrence of disease and survival in patients with endometrial cancer.

Methods: A retrospective study of 267 patients with endometrial carcinoma who underwent surgery at the Oncology CenterMansoura University from January 2011 to December 2017. Patients were divided according to their body mass index (BMI) into two groups, Group 1 with a BMI $<30$ and Group 2 with a BMI $\geq 30$.

Results: Group 1 included 46 patients and Group 2 included 221. The mean operative time was longer in Group 2 without statistically significant difference. Twenty-two (47.8\%) patients in Group 1 and 71 (32.1\%) in Group 2 underwent lymphadenectomy $(\mathrm{p}=0.062)$. The estimated blood loss was significantly higher in Group 2 ( $\mathrm{p}<0.05)$. No statistically significant difference was found between the two groups regarding the intra or post-operative complications, despite the high incidence of complications in Group 2. The median disease-free survival (DFS) was 74 months in Group 1 vs. 66 months in Group 2. Obesity did not have a statistically significant impact on DFS among the studied cases ( $p=0.24)$.

Conclusion: In the current study, obesity did not significantly impact the operative procedure, surgical complications or DFS in patient with endometrial cancer.

Keywords: Endometrial cancer, Obesity, Surgery, Complications, Disease recurrence, Survival

Corresponding author: Khaled Gaballa, MD; Department of Surgery, Oncology Center-Mansoura University, Mansoura, Egypt; Email: Khaledgaballah85@gmail.com

Submitted: 4-February-2020, Revised: 13-March-2020, Accepted: 21-March-2020, Published online: 1-April-2020

(cc) BY

\section{INTRODUCTION}

Obesity is a well-known risk factor for many health problems including cardiovascular diseases, type 2 diabetes and a number of cancers ${ }^{1}$. One of the most common cancers associated with obesity is endometrial cancer ${ }^{1}$. Many research works had been conducted to study the relation between obesity and increased risk of endometrial cancer ${ }^{2-4}$.

In addition to the increased risk of endometrial cancer in obese patients, obesity may act as an obstacle to achieving optimal treatment in patients already diagnosed with endometrial cancer. Several studies have discussed the impact of obesity on the surgical outcome and the survival rate among this group of patients ${ }^{5-8}$.

While the gold standard management for endometrial cancer is surgery whether by laparoscopy or open technique ${ }^{9,10}$, obese patients usually have a higher risk of intra and postoperative complications compared to patients with normal BMI ${ }^{5}$. Also, obese patients have problems considering the postoperative adjuvant treatment as a proportion of them may require postoperative adjuvant radiotherapy which is not easily applicable specially with morbid obesity ${ }^{11}$, as not all the radiotherapy machines can accommodate these weights specially in developing countries.

In this retrospective study, we investigated the impact of obesity among patients with endometrial cancer on the operative complications, postoperative outcomes, recurrence rate and survival.

\section{METHODS}

This retrospective study was approved by the Institution Review Board of the Faculty of Medicine Mansoura university (approval \# RP.19.06.32).

The institutional registry at the Oncology CenterMansoura University (OCMU) and the Clinical Oncology and Nuclear Medicine Department at Mansoura University hospitals were thoroughly revised for endometrial cancer patients treated in a 7-year period from January 2011 to December 2017. Patients were followed up till December 2018. 
We included women aged 18-75 years with a pathologically proven endometrial cancer who underwent surgery. Exclusion criteria were no definite pathologic diagnosis, endometrial sarcoma, second malignancy or inadequate data documentation.

The preoperative assessment of patients included a detailed history (age, associated comorbidities, previous laparotomy or abdominal surgery), physical examination (including weight, height and body mass index [BMI]), preoperative abdominopelvic magnetic resonance imaging or computed tomography, examination under anesthesia, tumor characteristics (pathological type, grade and International Federation of Gynecology and Obstetrics [FIGO] stage) and routine biochemical examination.

Complete operative data and intraoperative and postoperative complications information were collected in addition to other treatment modalities including radiotherapy and chemotherapy.

Obesity was defined as a BMI of $\geq 30$ and, accordingly, patients were divided into two groups. The BMI of Group 1 was $<30$ and that of Group 2 was $\geq 30$.

Data were analyzed using IBM SPSS software package version 22.0. Qualitative data were described as number and percent. Quantitative data were described as median (range) if non-parametric or mean (standard deviation) if parametric after testing normality using Kolmogrov-Smirnov test. Chi-Square test was used for comparison of two or more groups and Fischer Exact test was used as a correction for Chi-Square test when more than $25 \%$ of cells have count less than 5 in $2 * 2$ tables. The median duration of the follow up was calculated after the end of treatment. Survival data was calculated by KaplanMeier test and log rank test was used to test effect the of BMI on disease free survival (DFS). A p value $<0.05$ was considered significant.

\section{RESULTS}

Eighty-three patients were excluded from the study as they did not meet the inclusion criteria; 45 patients were not operated upon and the other 38 had endometrial sarcoma. Two hundred and sixty-seven patients were included in the study, $46(17.2 \%)$ in Group 1 (BMI <30) and $221(82.8 \%)$ patients in Group 2 (BMI $\geq 30)$.

The characteristics of patients with a comparison between the two groups are shown in Table 1. Only the prevalence of comorbidities differed significantly and was higher in Group 2. There was no significant difference between both groups regarding the pathological type, tumor grade, FIGO staging or previous laparotomy / laparoscopy. Fifteen $(32.6 \%)$ patients in Group 1 and $66(29.8 \%)$ in Group 2 did not receive adjuvant therapy $(\mathrm{p}=0.65)$.

Table 2 illustrates the operative details and the prevalence of complications in the two groups. All the patients with endometrioid pathology FIGO stage more than IB and patients with FIGO stage IA G3 underwent hysterectomy, bilateral salpingoophrectomy and pelvic lymphadenectomy. All other patients with other pathology types (clear cell, serous, carcinosarcoma) were planned for hysterectomy, bilateral salpingoophrectomy and pelvic +/- para-aortic lymphadenectomy with omentectomy. The operative time was longer in Group 2, but with no statistically significant value.

Table 1: Patients' characteristics according to obesity

\begin{tabular}{|c|c|c|c|}
\hline Item & $\begin{array}{l}\text { Group 1, } \\
\text { BMI<30 } \\
(n=46) \\
\end{array}$ & $\begin{array}{l}\text { Group 2, } \\
\text { BMI } \geq 30 \\
(n=221)\end{array}$ & P value \\
\hline & \multicolumn{2}{|c|}{ Mean \pm SD } & \\
\hline \multirow[t]{2}{*}{ Age (years) } & $59.7 \pm 8.82$ & $60.9 \pm 8.67$ & 0.16 \\
\hline & \multicolumn{2}{|c|}{$n(\%)$} & \\
\hline \multicolumn{4}{|l|}{ Co-morbidities } \\
\hline No & $22(47.8)$ & $64(28.9)$ & \multirow[t]{2}{*}{0.03} \\
\hline Yes & $24(52.2)$ & $157(71.1)$ & \\
\hline \multicolumn{4}{|l|}{$\begin{array}{l}\text { Previous laparotomy } \\
\text { / laparoscopy }\end{array}$} \\
\hline No & $34(73.9)$ & $189(85.5)$ & \multirow[t]{2}{*}{0.09} \\
\hline Yes & $12(26.1)$ & $32(14.5)$ & \\
\hline \multicolumn{4}{|l|}{ Pathology } \\
\hline Endometroid & $33(71.7)$ & $176(79.6)$ & \multirow[t]{4}{*}{0.52} \\
\hline Clear-cell & $4(8.7)$ & $12(5.4)$ & \\
\hline Serous & $7(15.2)$ & $21(9.6)$ & \\
\hline Carcinosarcoma & $2(4.3)$ & $12(5.4)$ & \\
\hline \multicolumn{4}{|l|}{ Grade } \\
\hline $\mathrm{I}$ & $15(32.6)$ & $71(32.1)$ & \multirow[t]{3}{*}{0.41} \\
\hline II & $17(37)$ & $101(45.7)$ & \\
\hline III & $14(30.4)$ & $49(22.2)$ & \\
\hline \multicolumn{4}{|l|}{ FIGO Stage } \\
\hline I & $28(60.9)$ & $149(67.4)$ & \multirow[t]{3}{*}{0.16} \\
\hline II & $10(21.7)$ & $36(16.3)$ & \\
\hline III & $8(17.4)$ & $36(16.3)$ & \\
\hline \multicolumn{4}{|l|}{$\begin{array}{l}\text { Neoadjuvant } \\
\text { chemotherapy }\end{array}$} \\
\hline No & $43(93.5)$ & $215(97.3)$ & \multirow[t]{2}{*}{0.13} \\
\hline Yes & $3(6.5)$ & $6(2.7)$ & \\
\hline \multicolumn{4}{|l|}{ Adjuvant therapy* } \\
\hline External beam RT & $22(47.8)$ & $120(54.2)$ & \multirow[t]{4}{*}{0.65} \\
\hline Brachytherapy & $7(15.2)$ & $31(14)$ & \\
\hline Chemotherapy & $6(13)$ & $18(8.1)$ & \\
\hline None & $15(32.6)$ & $66(29.8)$ & \\
\hline
\end{tabular}

RT: Radiotherapy; FIGO: International Federation of Gynecology and Obstetrics; * Some patients received more than one line of treatment

Overall, the prevalence of intraoperative and postoperative complications did not differ significantly between the 2 groups. Only one patient in Group 1 had an intraoperative complication in the form of injury of the external iliac vein which was repaired successfully. Seven patients in Group 2 experienced intraoperative complications; 3 patients had vascular injuries which were controlled, 2 patients had bladder tear that was repaired with leaving uretheral catheter in place for 10 days, one patient had ureteral injury that was repaired immediately with insertion of ureteric stent and the last one had an iatrogenic intestinal injury.

Two patients in Group 1 experienced post-operative wound infection. Regarding the post-operative complications in Group 2; 3 patients had deep venous thrombosis, 2 patients developed pulmonary embolism (managed successfully with anti-coagulants), 7 patients had postoperative lymphorrhea (managed conservatively in 5 patients while 2 patients required insertion of a tube 
drain), and 18 patients experienced postoperative wound infection. Only the estimated blood loss was significantly higher in Group 2.

Table 2: Operative data and complications according to obesity

\begin{tabular}{|c|c|c|c|}
\hline & $\begin{array}{l}\text { Group 1, } \\
\text { BMI<30 } \\
(n=46)\end{array}$ & $\begin{array}{l}\text { Group 2, } \\
\text { BMI } \geq \mathbf{3 0} \\
(n=\mathbf{2 2 1})\end{array}$ & $\begin{array}{l}\mathbf{P} \\
\text { value }\end{array}$ \\
\hline & \multicolumn{2}{|c|}{$n(\%)$} & \\
\hline \multicolumn{4}{|l|}{ Type of operation } \\
\hline $\mathrm{TAH}+\mathrm{BSO}$ & $24(52.2)$ & $150(67.9)$ & 0.052 \\
\hline $\mathrm{TAH}+\mathrm{BSO}+\mathrm{LN}$ & $19(41.3)$ & $67(30.3)$ & \\
\hline $\begin{array}{l}\mathrm{TAH}+\mathrm{BSO}+\mathrm{LN}+ \\
\text { Omentum }\end{array}$ & $3(6.5)$ & $4(1.8)$ & \\
\hline Lymphadenectomy & $22(47.8)$ & $71(32.1)$ & 0.062 \\
\hline $\begin{array}{l}\text { Intraoperative } \\
\text { complications }\end{array}$ & $1(2.2)$ & $7(3.1)$ & 0.66 \\
\hline \multirow[t]{2}{*}{$\begin{array}{l}\text { Post-operative } \\
\text { complications }\end{array}$} & $2(4.4)$ & $23(10.4)$ & 0.19 \\
\hline & \multicolumn{2}{|c|}{ Mean \pm SD } & \\
\hline $\begin{array}{l}\text { Operative time } \\
\text { (minutes) }\end{array}$ & $120 \pm 10$ & $180 \pm 30$ & 0.16 \\
\hline \multirow[t]{2}{*}{$\begin{array}{l}\text { Estimated blood loss } \\
(\mathrm{ml})\end{array}$} & $200 \pm 30$ & $400 \pm 50$ & $<0.05$ \\
\hline & \multicolumn{2}{|c|}{ Median (range) } & \\
\hline $\begin{array}{l}\text { Number of dissected } \\
\text { pelvic lymph nodes }\end{array}$ & $7(3-32)$ & $4(2-10)$ & 0.24 \\
\hline
\end{tabular}

TAH: Total abdominal hysterectomy, BSO: $\quad$ Bilateral salpingoophrectomy; LN: Lymphadenectomy

The median duration of follow up was 27 (9-85) months in Group 1 and 31 (10-98) in Group 2. Disease recurrence occurred in $8(17.4 \%)$ patients in Group 1 within median time of 9 months while 57 (25.8\%) patients had recurrence in Group 2 within a median time of 12 months $(\mathrm{P}=0.22)$. The median disease-free survival (DFS) in all studied patients was 67 months $(95 \%$ Confidence Interval [CI]: 59.92-74.07). In Group 1 median DFS was 74 months (95\% CI: 59.59-88.4), while in Group 2 it was 66 months (95\% CI: 55.24-76.75). The BMI did not have a statistically significant effect on DFS among the studied cases $(\mathrm{p}=0.24)$ (Figure 1$)$. By dividing patients according to BMI value of 40 ( $\leq 40$ vs. $>40)$, the recurrence was 30 among $118(25.4 \%)$ patients vs. 35 among $149(23.4 \%)$, with insignificant difference $(\mathrm{p}=0.71)$. The median DFS in patients with BMI $>40$ was 60 months (95\% CI: 57.85-74.83) compared to 66 months $(95 \%$ CI: 53.27-67.71) in patients with BMI $\leq 40$ $(\mathrm{P}=0.053)$ (Figure 2).

\section{DISCUSSION}

Obesity is a well-known global problem that is contributing to many health problems. Egypt is a one of the most affected countries by obesity. In a report from previous study, it was found that around 19 million Egyptians representing about $35 \%$ of adults were obese. Also, more than 10 percent which represents about 3.6 million of children were considerably overweight ${ }^{8}$. In our study, we examined the impact of obesity on the operative complications and recurrence in patients with endometrial cancer in an Egyptian cancer care setting.

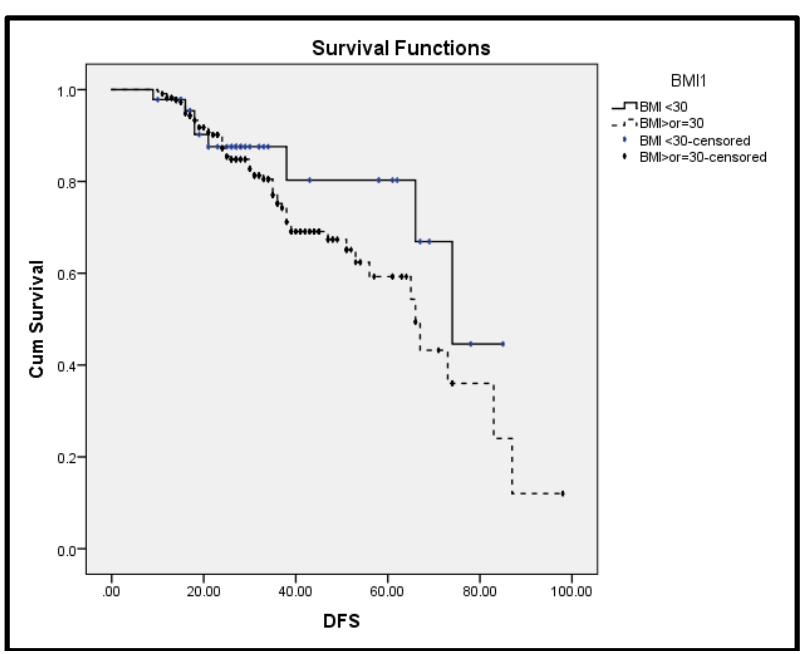

Figure 1: Kaplan Meier Curves of disease-free survival according to BMI cutoff value of 30

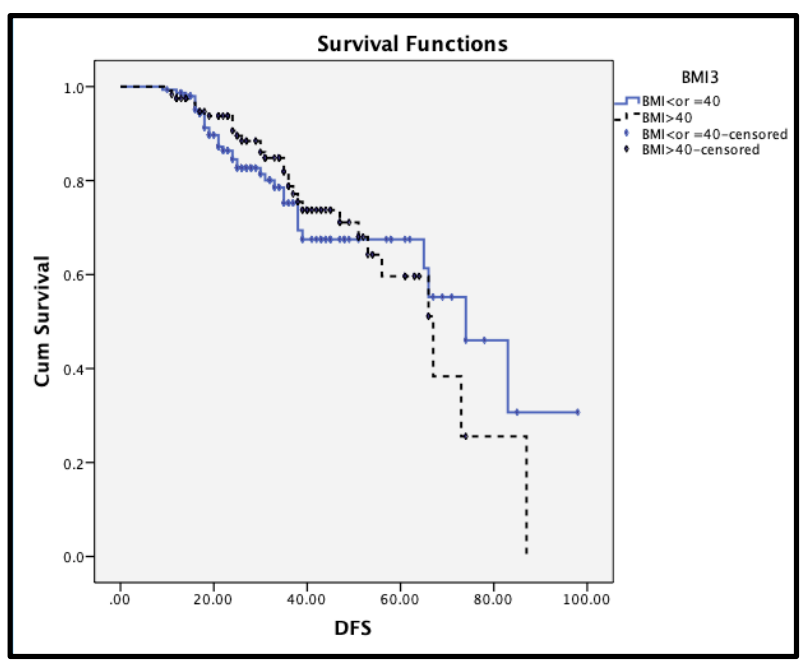

Figure 2: Kaplan Meier Curves of disease-free survival according to BMI cutoff value of 40

Type I endometrial cancers were more common in obese patients in our study as reported by others ${ }^{12-14}$. As regard the operative procedures, obesity did not significantly impact the surgical procedures in both groups as regard the number of patients who underwent lymphadenectomy, the median number of harvested lymph nodes and the intraoperative complications. However, the obese group had significantly more blood loss than the non-obese group. The higher blood loss in obese patients was reported in several previous studies ${ }^{15-}$ 17. The operative time was reported to be significantly longer in obese patients in some studies ${ }^{16,18}$. Although the operative time was longer among obese patients in our study, this was not statistically significant as also reported by other retrospective studies 18, 19 . Similar to our findings, Erkanli et al, Santoso et al and Rabischong et al reported that the intra and post-operative complication rates did not differ significantly between the obese and non-obese patients ${ }^{7,16,19}$. 
Von Gruenign et al. stated that obesity is associated with higher mortality rates attributed to causes other than endometrial cancer and not the disease recurrence ${ }^{20}$. Also, Modesitt et al did not find significant association between progression free survival and $\mathrm{BMI}^{21}$. In another two studies, obesity did not affect the overall survival of endometrial cancer patients who underwent surgery ${ }^{22,23}$. Our finding that obesity did not affect DFS confirms the lack of association between obesity and survival reported by these studies.

This study has a number of limitations including that the study was retrospective, not all the patients were operated by the same surgeons, the number of patients with BMI <30 was relatively low in our locality and the relatively short period of follow up.

\section{Conclusion}

In our study, obesity did not have a significant impact on postoperative complications or DFS of endometrial cancer patients who underwent surgery. However, our study had a number of limitations necessitating future better-designed studies with longer follow up to consolidate the results.

\section{CONFLICT OF INTEREST}

The authors have no conflict of interest to disclose.

\section{REFERENCES}

1. Reeves GK, Pirie K, Beral V, et al. Cancer incidence and mortality in relation to body mass index in the Million Women Study: cohort study. BMJ. 2007; 335 (7630): 1134.

2. Calle EE, Kaaks R. Overweight, obesity and cancer: epidemiological evidence and proposed mechanisms. Nat Rev Cancer. 2004; 4(8): 579-591.

3. Renehan AG, Tyson M, Egger M, Heller RF, Zwahlen M. Body-mass index and incidence of cancer: a systematic review and meta-analysis of prospective observational studies. Lancet. 2008; 371(9612): 569-578.

4. Fambrini M, Pieralli A, Bitossi U, et al. Mini-laparotomy versus vaginal surgery for class II-III obese patients with early-stage endometrial cancer. Anticancer Res. 2012: 32(2): 707-712.

5. Orekoya O, Samson ME, Trivedi T, Vyas S, Steck SE. The impact of obesity on surgical outcome in endometrial cancer patients: a systematic review. J Gynecol Surg. 2016: 32(3): 149-157.

6. Subramaniam A, Kim KH, Bryant SA, et al. A cohort study evaluating robotic versus laparotomy surgical outcomes of obese women with endometrial carcinoma. Gynecol Oncol. 2011; 122(3): 604-607.

7. Erkanli S, Kayaselçuk F, Bagis T, Kuşçu E. Impact of morbid obesity in surgical management of endometrial cancer: surgical morbidity, clinical and pathological aspects. Eur J Gynaecol Oncol. 2006; 27(4): 401-404.
8. GBD 2015 Obesity Collaborators, Afshin A, Forouzanfar $\mathrm{MH}$, et al. Health effects of overweight and obesity in 195 countries over 25 years. N Engl J Med. 2017: 377(1): 13-27.

9. Press JZ, Gotlieb WH. Controversies in the treatment of early stage endometrial carcinoma. Obstet Gynecol Int. 2012; 2012: 578490.

10. Amant F, Moerman P, Neven P, Timmerman D, Van Limbergen E, Vergote I. Treatment modalities in endometrial cancer. Curr Opin Oncol. 2007; 19(5): 479-485.

11. Moszyńska-Zielińska M, Chałubińska-Fendler J, Gottwald L, Żytko L, Bigos E, Fijuth J. Does obesity hinder radiotherapy in endometrial cancer patients? The implementation of new techniques in adjuvant radiotherapy - focus on obese patients. Prz Menopauzalny. 2014; 13(2): 96-100.

12. Cusimano MC, Simpson AN, Han A, et al. Barriers to care for women with low-grade endometrial cancer and morbid obesity: a qualitative study. BMJ Open. 2019; 9(6): e026872.

13. Bokhman JV. Two pathogenetic types of endometrial carcinoma. Gynecol Oncol. 1983; 15(1): 10-17.

14. Modesitt SC, van Nagell JR Jr. The impact of obesity on the incidence and treatment of gynecologic cancers: a review. Obstet Gynecol Surv. 2005; 60(10): 683-692.

15. Giugale LE, Di Santo N, Smolkin ME, Havrilesky LJ, Modesitt SC. Beyond mere obesity: effect of increasing obesity classifications on hysterectomy outcomes for uterine cancer/hyperplasia. Gynecol Oncol. 2012; 127(2): 326-331.

16. Santoso JT, Barton G, Riedley-Malone S, Wan JY. Obesity and perioperative outcomes in endometrial cancer surgery. Arch Gynecol Obstet. 2012; 285(4): 1139-1144.

17. Pavelka JC, Ben-Shachar I, Fowler JM, et al.Morbid obesity and endometrial cancer: surgical, clinical, and pathologic outcomes in surgically managed patients. Gynecol Oncol. 2004; 95(3): 588-592.

18. Akbayır O, Corbacioglu Esmer A, Numanoglu C, et al. Influence of body mass index on clinicopathologic features, surgical morbidity and outcome in patients with endometrial cancer. Arch Gynecol Obstet. 2012; 286(5): 1269-1276.

19. Rabischong B, Larraín D, Canis M, et al. Long-term followup after laparoscopic management of endometrial cancer in the obese: a fifteen-year cohort study. J Minim Invasive Gynecol. 2011; 18(5): 589-596.

20. von Gruenigen VE, Tian C, Frasure H, Waggoner S, Keys $\mathrm{H}$, Barakat RR. Treatment effects, disease recurrence, and survival in obese women with early endometrial carcinoma : a Gynecologic Oncology Group study. Cancer. 2006; 107(12): 2786-2791.

21. Modesitt SC, Tian C, Kryscio R, et al. Impact of body mass index on treatment outcomes in endometrial cancer patients receiving doxorubicin and cisplatin: a Gynecologic Oncology Group study. Gynecol Oncol. 2007; 105(1): 5965.

22. Jeong NH, Lee JM, Lee JK, et al. Role of body mass index as a risk and prognostic factor of endometrioid uterine cancer in Korean women. Gynecol Oncol. 2010; 118(1): 2428.

23. Gambacorti-Passerini ZM, Lopez-De la Manzanara Cano C, Perez Parra C, et al. Obesity in patients with endometrial cancer: may it affect the surgical outcomes of laparoscopic approach? Obes Surg. 2019; 29(10): 3285-3290. 